\title{
Non-invasive methods for morphometric analyses of lepidopteran wings
}

\author{
Mihai A. Martin, Cristian Sitar \& László Rákosy
}

\begin{abstract}
Summary: Butterfly wings are commonly used in morphometric studies. For this reason they are detached from the body in order to get a clearer image for the analysis. In some cases this is not desirable as it would destroy a butterfly that may have greater value displayed. Our results show that displayed butterflies can also be used in morphometric analyses.
\end{abstract}

Key words: butterfly, wing, morphometrics, displayed, detached, Melanargia galathea.

\section{Introduction}

Geometric and traditional morphometric measurements (ZeLDITCH et al. 2004) have been used successfully in many studies of wing shape and wing pattern variation among butterflies (DESCIMON \& ReNON 1975, LuebKe et al. 1988, DudLey 1990, MONTEIRO et al. 1997, Winding et al. 2001, BREUKER et al. 2010, DiNCĂ et al. 2011, GiBBS et al. 2011, JoRGE et al. 2011, CESPEDES et al. 2014, HABEL et al. 2016, MarTin et al. 2016). Modern technology could even allow automatisation of such forms of analysis (Houle et al. 2003). These measurements are often done on detached wings, as they are easier to manipulate and the risk of error is reduced. Live specimens can be photographed in the field and then released with the method developed by NÈVE \& Descimon (2005), so the problem arises when dealing with displayed butterflies, belonging to a collection or an endangered species, which would be damaged by wing detachment.

For this reason we attempted to determine if there are statistically significant differences between morphometric measurements of detached and displayed wings. Melanargia galathea (Linnaeus, 1758) butterflies were used as they are a common, non-endangered species and their wings have clear patterns that make landmarks easy to identify.

\section{Materials and methods}

Melanargia galathea butterflies were caught in June 2016 near the city of Răscruci (Cluj county, Romania), they were later displayed on a wooden support. Hairs close to the base of the wings were removed for a clearer picture. An insect pin was used to hold the butterfly in a still position while displayed. 10 male $M$. galathea butterflies were used in the analysis, in order to avoid any issues caused by sexual dimorphism. Three sets of measurements were made.

For the first analysis we tested if there was variation due to human error while placing the displayed butterflies on the stand to be photographed. The ten butterflies were photographed in two separate sessions, forming two groups of pictures.

For the second analysis we tested whether there was a difference at an individual level between displayed and detached wings. To do this a single butterfly was photographed ten times with the wings attached and then another ten times with the wings detached, these were the two groups of pictures then compared.

The third analysis was similar to the second but with all ten butterflies. They were first photographed with the wings attached and then with the wings detached, the two sets of pictures making the two groups used for comparison.

The displayed butterflies were photographed on graph paper, with great care taken so that the insect pin passing through the thorax was at a perpendicular angle to the wings. The Canon EOS 500D camera was placed on a tripod for a fixed position. The detached wings were photographed a second time, placed over graph paper and through a stereomicroscope using an Optika M HDMI 5 MP camera.

The digital photographs were converted to the TPS format using the software TPSUtil, which allows them to be processed in a system of coordinates. Landmarks (BOOKSTEIN 1986) were placed with the program TPSDig2 (http://life.bio.sunysb.edu/ morph/soft-utility.html), the placement was at the 
base of the wing at the split of the main vein and on the intersection of wing veins with the wing edge, the right forewing was the one analyzed (Fig. 1). Differences among individuals was tested using Principal Component Analysis, as this method reduces the dimensionality of multivariate data and allows easy graphical representation using the axes that cover the majority of the variation. The statistical differences were calculated using a Permutation test as our values might not follow a normal distribution and this test can reach a conclusion without assuming any distribution (ZELDITCH et al. 2004). Principal Component Analysis (PCA) and the Permutation Test were calculated using the program MorphoJ (http:// www.flywings.org.uk/morphoj_page.htm).

\section{Results}

The first analysis, employing ten displayed butterflies photographed twice, showed no statistically significant value for the permutation test: $\mathrm{p}=0.9947$ after 10000 permutations. Principal component analysis (PCA) also shows a fairly homogenous distribution (Fig. 2).

The second analysis, the wings of the same individual photographed ten times displayed and then detached, had a statistically significant result: $p<0.0001$ for the permutation test after 10000 permutation.
PCA (Fig. 3) shows clustered distributions for the two groups.

The third analysis, the wings of ten individuals photographed displayed and then detached, did not show a statistically significant difference: $\mathrm{p}=0.7768$ after 10000 permutations. Once again PCA (Fig. 4) shows an overlapped distribution.

\section{Discussion}

Our results show that displayed butterflies can be used in morphometric comparisons but only under certain conditions. Great care has to be taken when preparing the material for photography. In our case the greatest variation could have been given by the angle of the wings with the camera lens, by making sure that the wings were parallel to the base we obtained homogenous photographs that were not statistically different from each other, as shown by our first analysis.

Our second and third comparisons showed that variation when comparing displayed wings to detached wings is significant only when the sample size is small.

In conclusion we can affirm that, while detached wings are preferred for morphometric studies, displayed wings can be used if the situation demands it as long as large sample sizes are used. These results

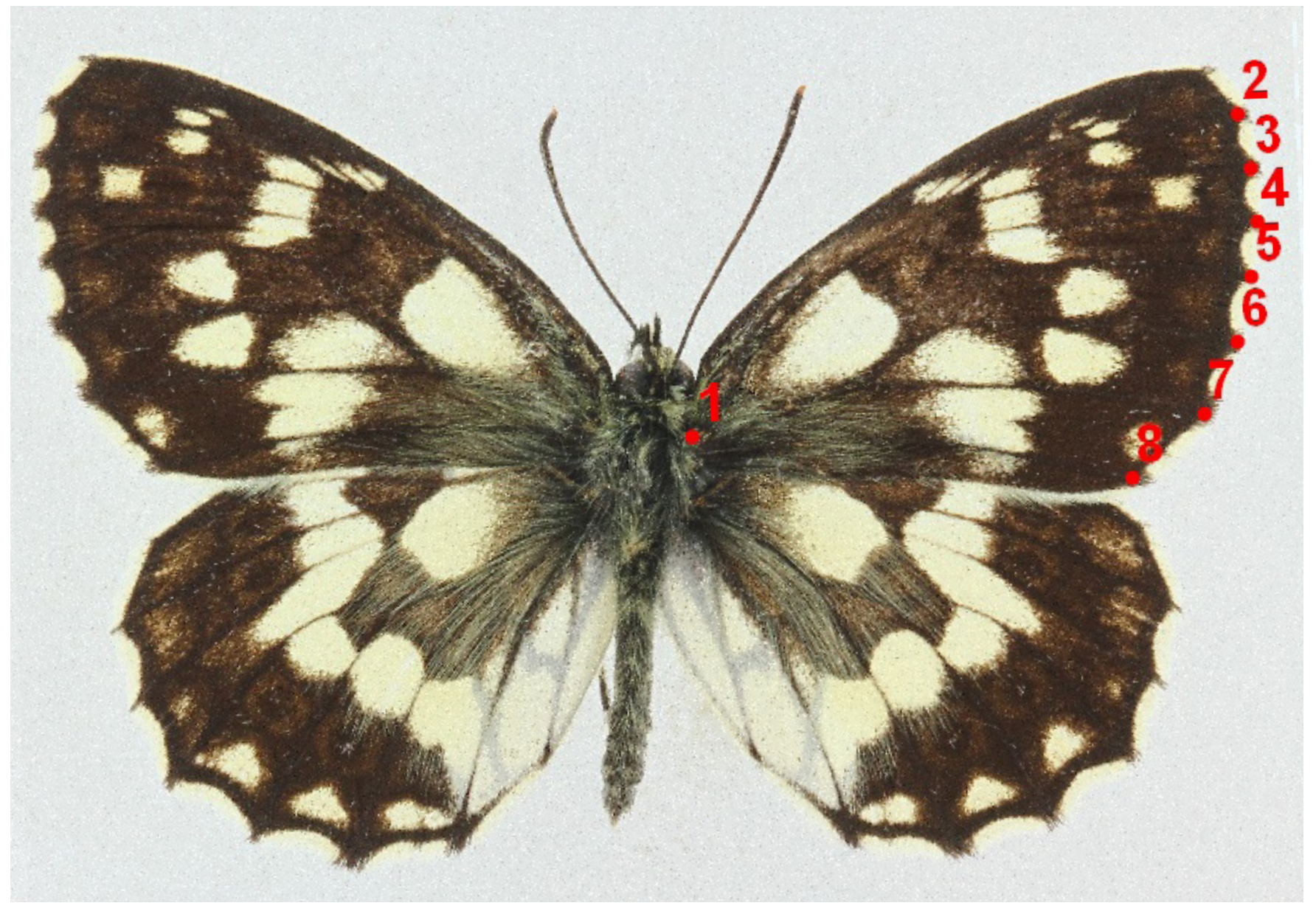

Fig. 1. Landmark placements on the right wing of a displayed male Melanargia galathea butterfly. 


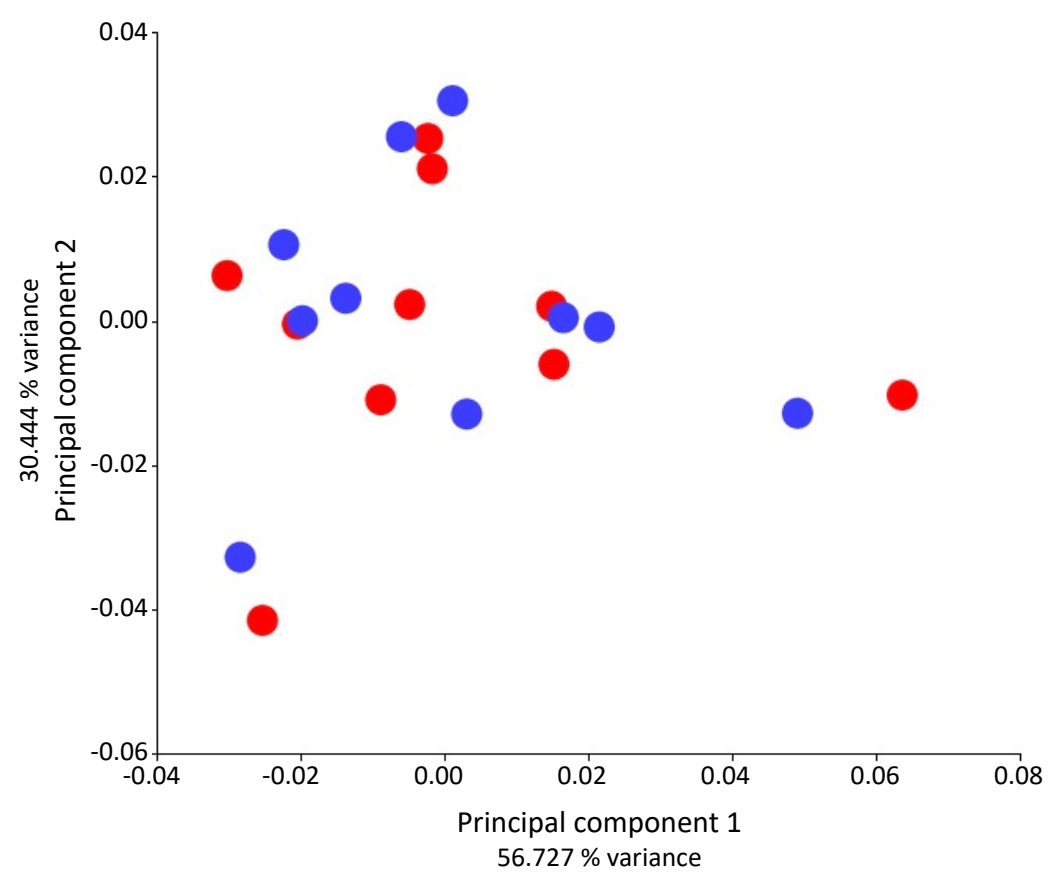

Fig. 2. First and second PCA axes for the first analysis covering $87.171 \%$ of the variance, ten displayed butterflies photographed twice, with blue dots representing results from the first set of photographs and red from the second set.

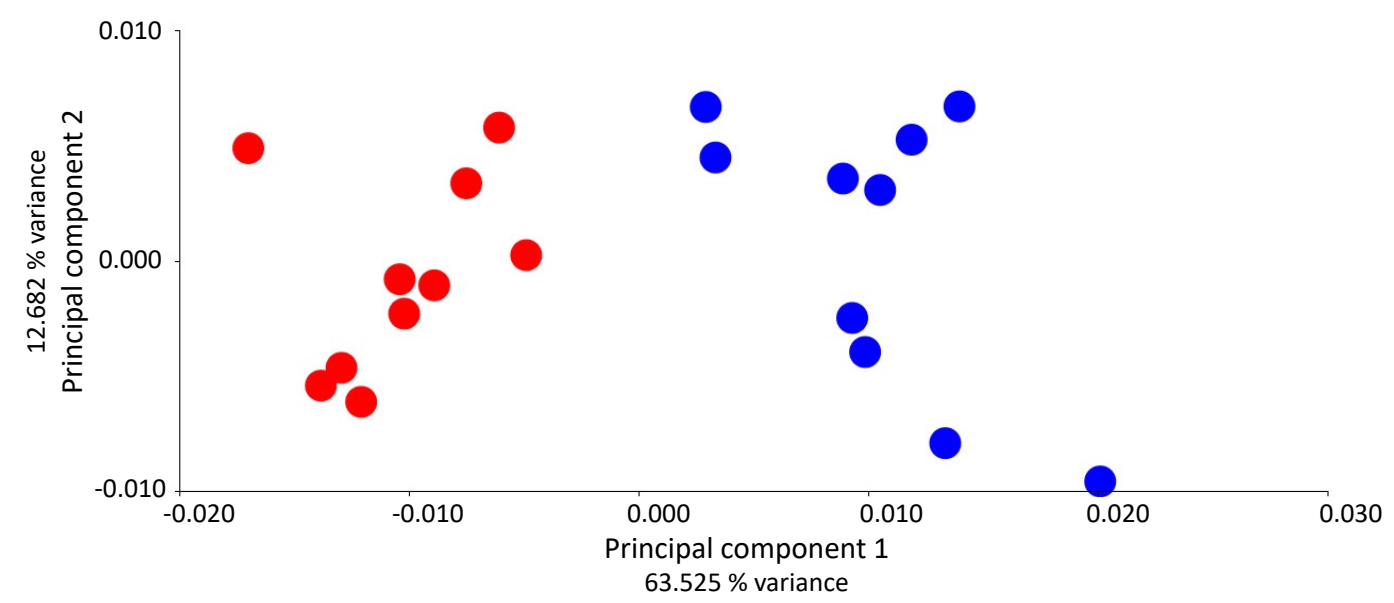

Fig. 3. First and second PCA axes for the second analysis covering $76.206 \%$ of the variance, the wings of the same individual photographed ten times displayed (blue) and then detached (red).

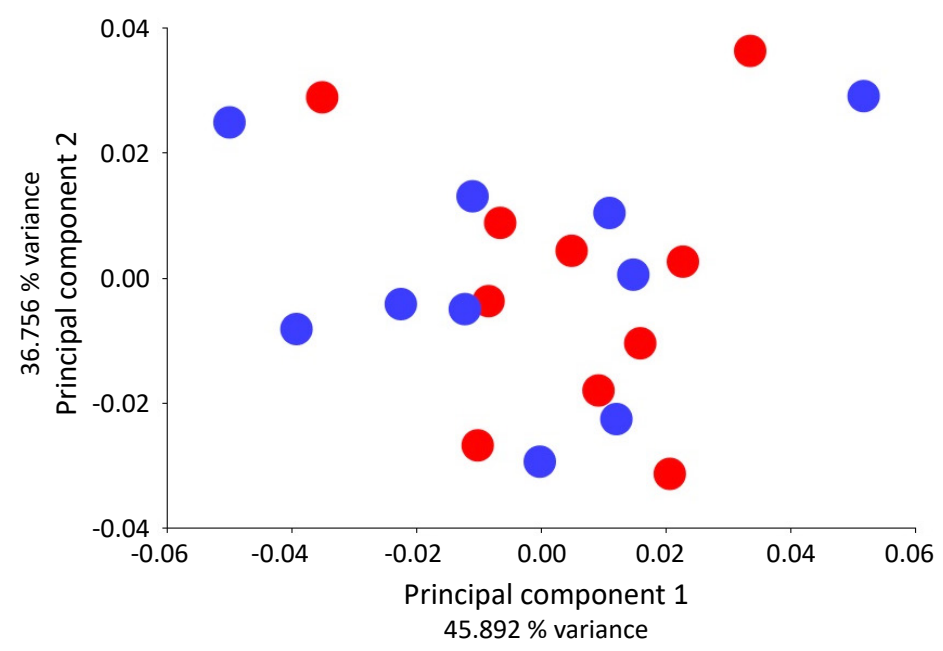

Fig. 4. First and second PCA axes for the third analysis covering $82.648 \%$ of the variance, the wings of ten individuals photographed displayed (blue) and then detached (red). 
show that non-invasive methods can be used in morphometric studies on lepidopteran wings, sparing the live of the individuals used in the analysis or protecting valuable pieces from collections.

\section{Acknowledgements}

The authors would like to thank Dr. Gabriel Nève and Dr. Edit Juhász for their help and guidance.

\section{References}

Breuker C.J., Gibbs M., Van Dongen S., Merckx T. and VAN DYcK H. (2010) The use of geometric morphometrics in studying butterfly wings in an evolutionary ecological context. In: ELVA M.T (ed.): Morphometrics for nonmorphometricians, Lecture notes in Earth sciences. Springer-Verlag, Berlin Heidelberg, Germany.

BooKSTEIN F.L. (1986) Size and shape spaces for Landmark data in two dimensions. Statistical science 1 (2): 181242.

Cespedes A., Penz C. M. and Devries P.J. (2014) Cruising the rain forest floor: butterfly wing shape evolution and gliding in ground effect. Journal of Animal Ecology 84 (3): 808-816.

Descimon H. and Renon C. (1975) Mélanisme et facteurs climatiques: I - Étude biométrique de la variation de Melanargia galathea (LinNÉ) (Lepidoptera Satyridae) en France. Archives de zoologie expérimentale et générale 116: 255-292.

Dincă V., Dapporto L. and Vila R. (2011) A combined genetic-morphometric analysis unravels the complex biogeographical history of Polymmatus icarus and Polymmatus celina Common Blue butterflies. Molecular Ecology 20: 3921-3935.

DudLEY R. (1990) Biomechanics of flight in neotropical butterflies: morphometrics and kinematics. Journal of experimental Biology 150: 37-53.

Gibis M., Wiklund C. and Van Dyck H. (2011) Phenotypic plasticity in butterfly morphology in response to weather conditions during development. Journal of Zoology 238: 162-168.

Habel J.C., Vila R., Vodă R., Husemann M., Schmitt T. and DAPPORTO L. (2016) Differentiation in the marbled white butterfly species complex driven by multiple evolutionary forces. Journal of Biogeography 44 (2): 433-445.

Houle D., Mezey J., Galpern P. and Carter A. (2003) Automated measurement of Drosophila wings. BMC Evolutionary Biology 3: 25.

LuebKe H.J., SCRIBER J.M. and Yandell B.S. (1988) Use of Multivariate Discriminant Analysis of male wing morphometrics to delineate a hybrid zone for Papilio glaucus glacus and P. g. canadensis in Wisconsin. American Midland Naturalist 119 (2): 366-379.

Martin M.A., Craioveanu C., Sitar C., Rákosy L. (2016) Why morphometrics: a short review and a case study on Zygaena carniolica (ScOPOLI, 1763). Entomologica romanica 20: 57-62.

Monteiro A., Brakefield P.M., and French V. (1997) The relationship between eyespot shape and wing shape in the butterfly Bicyclus anynana: A genetic and morphological approach. Journal of Evolutionary Biology 10: 787-802.

NÈVE G. and Descimon H. (2005) Non-lethal way of securing insect specimens in the field for morphometrics studies. Bulletin de la Société royale belge d'Entomologie. 141: 185-187.

Winding J.J., RintamäKi P.T., CAssel A. and Nylin S. (2001): How useful is fluctuating asymmetry in conservation biology: Asymmetry in rare and abundant Coenonympha butterflies. Journal of Insect Conservation 4: 253-261.

Zelditch M.L., Swiderski D.L., SheEts H.D., FinK W.L. (2004) Geometric Morphometrics for biologists: A primer. Elsevier Academic Press, USA pp: 444.
Mihai A. MARTIN

Doctoral School in Integrative Biology Babeș-Bolyai University,Universității 7-9 Cluj-Napoca, Romania

E-mail:mihai_alexandru.martin@yahoo.com
Cristian SITAR

Zoological Museum

Babeș-Bolyai University, Clinicilor 5-7

Cluj-Napoca, Romania

E-mail: cristiansitar@yahoo.com
László RÁKOSY

Department of Taxonomy and Ecology Babeș-Bolyai University, Clinicilor 5-7 Cluj-Napoca, Romania

E-mail: laszlorakosy@ubbcluj.ro

Received: 31.05 .2020

Accepted: 31.08 .2020

Published online: 30.09 .2020

Published: 31.12.2020

Online article number: ER24202003

doi: 10.24193/entomolrom.24.3 